J. Electroanal. Chem., 246 (1988) 441-447

Elsevier Sequoia S.A., Lausanne - Printed in The Netherlands

Short communication

\title{
COMPETITIVE ELECTROFORMATION OF SILVER AND OXYGEN OVERLAYERS ON POLYCRYSTALLINE RHODIUM IN ACID
}

\author{
B.S. PARAJÓN COSTA, N.R. DE TACCONI, M.C. GIORDANO and A.J. ARVIA \\ Instituto de Investigaciones Fisicoquimicas Teóricas y Aplicadas (INIFTA), Facultad de Ciencias Exactas, \\ Universidad Nacional de La Plata, Casilla de Correo 16, Sucursal 4, 1900 La Plata (Argentina)
}

(Received 10th May 1987; in revised form 13th January 1988)

\section{INTRODUCTION}

The stripping analysis of metal layers at solid electrodes is considerably influenced by strong interactions at the deposited monolayer level [1,2]. For various systems the underpotential deposition (UPD) of metals occurs within a potential range where another surface process such as O-electrosorption takes place simultaneously. In this case the interactions at the metal UPD level can be modified significantly. Some of these effects can be observed in voltammetric studies of UPD of $\mathrm{Ag}$ on $\mathrm{Pt}$ performed with $\mathrm{Pt}$ ring-disc electrodes [3], accompanied by the inhibition of hydrogen adsorption on Pt [4], the displacement of adsorbed hydrogen by UPD $\mathrm{Ag}$ and $\mathrm{Cu}[5,6]$, and UPD and overpotential deposition (OPD) of $\mathrm{Ag}$ on Pt [7].

In the present work results obtained for $\mathrm{Ag}$ deposition on polycrystalline $\mathrm{Rh}$ in $\mathrm{H}_{2} \mathrm{SO}_{4}+\mathrm{Ag}_{2} \mathrm{SO}_{4}$ solutions are reported. This system offers a relatively wide potential range where both reactions, namely, the UPD of $\mathrm{Ag}$ and O-electrodesorption can be studied either simultaneously or independently.

\section{EXPERIMENTAL}

The working electrode was a polycrystalline (pc) Rh wire (Johnson Matthey Chemical Co, Spec-pure, $0.1 \mathrm{~mm}$ dia., $0.59 \mathrm{~cm}^{2}$ apparent area). The electrode pretreatment was the same as described previously [8]. A Rh counterelectrode and a $\mathrm{Hg} / \mathrm{Hg}_{2} \mathrm{SO}_{4} / 1 M \mathrm{H}_{2} \mathrm{SO}_{4}$ reference electrode were employed, but potentials in the text are referred to the reversible hydrogen electrode in the same solution (RHE). The electrolyte solution was $1 \mathrm{M} \mathrm{H}_{2} \mathrm{SO}_{4}$ which was prepared from $98 \% \mathrm{H}_{2} \mathrm{SO}_{4}$ (Merck AR) and purified distilled water (Milli $\mathrm{Q}^{\circledR}$ ). $\mathrm{Ag}_{2} \mathrm{SO}_{4}$ (Mallinckrodt, p.a.) was added to the electrolyte in the $10^{-5}$ to $10^{-3} M$ range. The experiments were 
made with nitrogen saturated solutions in the $0-65^{\circ} \mathrm{C}$ range by using triangular potential scanning combined with potential steps $[8,9]$.

\section{RESULTS AND DISCUSSION}

A typical voltammogram of the pc Rh electrode in $1 \mathrm{MH}_{2} \mathrm{SO}_{4}+2.5 \times 10^{-4} \mathrm{M}$ $\mathrm{Ag}_{2} \mathrm{SO}_{4}$ in the $E_{\mathrm{s}, \mathrm{c}}=0.03 \mathrm{~V}$ to $E_{\mathrm{s}, \mathrm{a}}=1.4 \mathrm{~V}$ range at $0.1 \mathrm{~V} / \mathrm{s}$ is shown in Fig. 1 . The main anodic current contributions in the entire potential range are the remaining $\mathrm{H}$-electrodesorption $\left(\mathrm{I}_{\mathrm{H}, \mathrm{a}}\right)$ at ca. $0.1 \mathrm{~V}$, an asymmetric peak $\left(\mathrm{II}_{\mathrm{a}}\right)$ at $0.75 \mathrm{~V}$, preceded by a shoulder at $0.6 \mathrm{~V}\left(\mathrm{II}_{\mathrm{a}}^{\prime}\right)$ and followed by a hump at $0.85 \mathrm{~V}\left(\mathrm{II}_{\mathrm{a}}^{\prime \prime}\right)$, and the constant current region (III ${ }_{\mathrm{a}}$ ) due to Rh oxide formation extending from ca. $1.0 \mathrm{~V}$ upwards. The current peaks $\mathrm{II}_{\mathrm{a}}, \mathrm{II}_{\mathrm{a}}^{\prime}$ and $\mathrm{II}_{\mathrm{a}}^{\prime \prime}$ are related to the stripping of the different $\mathrm{Ag}$ layers competing with the $\mathrm{Rh}$ oxide formation in the low potential region (see $\mathrm{Ag}^{+}$ion-free voltammogram, dotted line in Fig. 1) [8,9].

The electroreduction scan exhibits a wide cathodic peak $\left(\mathrm{III}_{\mathrm{c}}\right)$ at ca. $0.45 \mathrm{~V}$ and the $\mathrm{H}$-electroadsorption peak $\left(\mathrm{I}_{\mathrm{H}, \mathrm{c}}\right)$ at $0.1 \mathrm{~V}$. The sequential formation of the different $\mathrm{Ag}$ layers becomes evident as $E_{\mathrm{s}, \mathrm{a}}$ is decreased stepwise from $1.4 \mathrm{~V}$ downwards. Peak III $_{c}$ shifts to more positive potentials and decreases gradually while the shoulder at $0.6 \mathrm{~V}\left(\mathrm{II}_{\mathrm{a}}^{\prime}\right)$ becomes an anodic current peak. Further on, two cathodic peaks ( $\mathrm{II}_{\mathrm{c}}$ and $\mathrm{II}_{\mathrm{c}}^{\prime}$ ), which correlate with the corresponding anodic peaks, are progressively distinguished. The $\mathrm{H}$-electrodesorption charge decreases systemati-

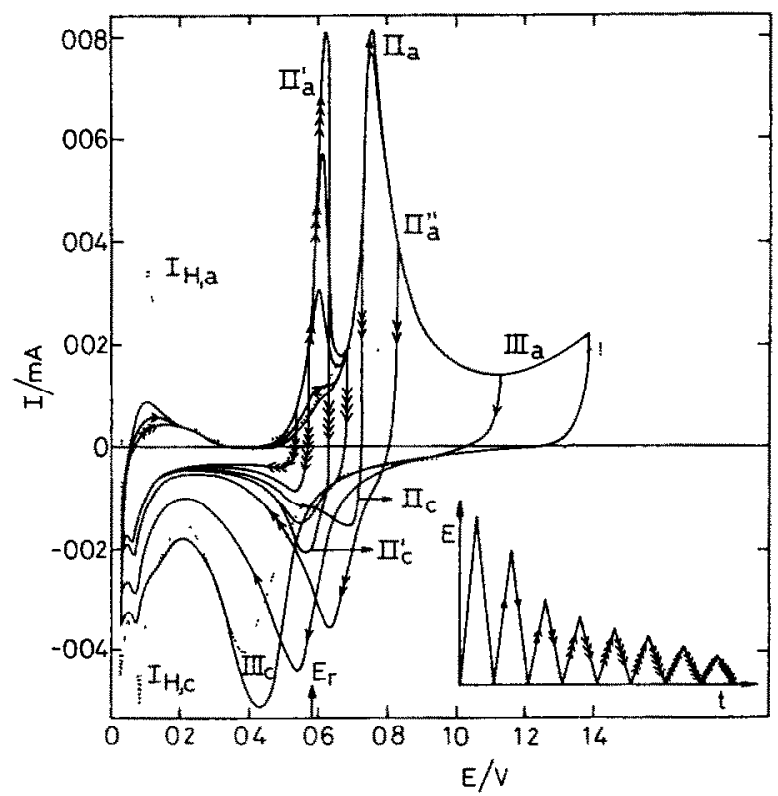

Fig. 1. Sequence of voltammograms on pc Rh in $1 \mathrm{M} \mathrm{H}_{2} \mathrm{SO}_{4}+2.5 \times 10^{-4} \mathrm{M} \mathrm{Ag}_{2} \mathrm{SO}_{4}$ by decreasing stepwise $E_{\mathrm{s}, \mathrm{a}}, E_{\mathrm{r}}$ indicates the $\mathrm{Ag} / \mathrm{Ag}^{+}$reversible potential. $25^{\circ} \mathrm{C}$. 
cally since the stripping of the $\mathrm{Ag}$ layers is not fully accomplished for $E_{\mathrm{s}, \mathrm{a}}<1.0 \mathrm{~V}$. Silver ion electrodeposition takes place continuously for $E_{\mathrm{s}, \mathrm{c}}<E_{\mathrm{r}}, E_{\mathrm{r}}$ being the reversible potential.

Similar results are obtained by decreasing the $\mathrm{Ag}_{2} \mathrm{SO}_{4}$ concentration down to $10^{-5} M$, but in this case peaks $\mathrm{II}_{\mathrm{a}}^{\prime}$ and $\mathrm{II}_{\mathrm{c}}^{\prime}$ are not evident unless a certain holding time, $\tau$, at $E_{\mathrm{s}, \mathrm{a}}^{\prime} \leqslant E_{\mathrm{r}}$ is included. For $0.6 \mathrm{~V}<E_{\mathrm{s}, \mathrm{a}}^{\prime}<0.8 \mathrm{~V}$, peak $\mathrm{III}_{\mathrm{c}}$ becomes wider and its charge smaller than that obtained in $\mathrm{Ag}^{+}$ion-free solution, while for 1.0 $\mathrm{V} \leqslant E_{\mathrm{s}, \mathrm{a}}^{\prime} \leqslant 1.3 \mathrm{~V}$, the total charge of peak $\mathrm{III}_{\mathrm{c}}$ is equivalent to that obtained in $\mathrm{Ag}^{+}$ ion-free $1 \mathrm{M} \mathrm{H}_{2} \mathrm{SO}_{4}$ solution. Thus, the charge related to the stripping of $\mathrm{Ag}$ layers can be evaluated as the total positive charge $\left(Q_{\mathrm{a}}^{\mathrm{T}}\right)$ for $E_{\mathrm{s}, \mathrm{a}}>1.0 \mathrm{~V}$ minus the negative charge $\left(Q_{\mathrm{c}}^{\mathrm{T}}\right)$ related to the electroreduction of O-containing species independently of its electroformation potential.

The electrodeposition of $\mathrm{Ag}^{+}$ions is influenced by the presence of the O-containing surface species on the substrate. This can be studied through the stripping voltammogram including a holding potential $E_{s}^{\prime}$ during a certain time $\tau$ either in the positive $\left(E_{\mathrm{s}, \mathrm{a}}^{\prime}\right)$ or negative $\left(E_{\mathrm{s}, \mathrm{c}}^{\prime}\right)$ potential scan. For $E_{\mathrm{s}, \mathrm{a}}^{\prime}>E_{\mathrm{r}}$ (Fig. 2a), Ag UPD takes place on a surface free of O-containing surface species, and the stripping voltammogram shows first the increase in height of peak $\mathrm{II}_{\mathrm{a}}^{\prime \prime}$ and later the appearance of peak $\mathrm{II}_{\mathrm{a}}$. These changes occur simultaneously with the decrease of the anodic current around $0.6 \mathrm{~V}$ which is related to $(\mathrm{RhOH})_{\text {ad }}$ formation $[8,9]$. The electroreduction scan shows an increasing charge for peak $\mathrm{III}_{\mathrm{c}}$ due to the electrodeposition of $\mathrm{Ag}$ and the electroreduction of O-containing species occurring simultaneously. The voltammograms depicted in Fig. $2 \mathrm{~b}$ show the influence of the $\mathrm{O}$-containing $\mathrm{Rh}$ surface on Ag UPD. The processes during the negative scan involve mainly the electroreduction of the fraction of $\mathrm{O}$-species remaining at the surface after the potential hold and the H-electroadsorption. The diffusion-controlled electrodeposition of $\mathrm{Ag}^{+}$ion interferes with both processes. The stripping voltammogram depicted in Fig. $2 c$ was obtained after applying a potential step during the electroreduction scan at an $E_{\mathrm{s}, \mathrm{c}}^{\prime}$ value close to $E_{\mathrm{r}}$. Under these circumstances the substrate is covered by only a fraction of the O-containing surface species. The characteristics of peak $\mathrm{II}_{\mathrm{a}}$ as well as the rest of the voltammogram depend strongly on $\tau$. The O-electroadsorption charge is considerably smaller than that observed in Fig. $2 \mathrm{~b}$ for $\tau \leqslant 120 \mathrm{~s}$. Otherwise, the cathodic current contribution at the positive side of peak III $_{c}$ increases according to the height of peak $\mathrm{II}_{\mathrm{a}}$ for $\tau>120 \mathrm{~s}$. Therefore, peak $\mathrm{II}_{\mathrm{a}}$ results from the stripping UPD Ag and formation of the $\mathrm{O}$-containing surface species on pc $\mathrm{Rh}$, and its contribution becomes considerable for $\tau>300 \mathrm{~s}$. In this case, when the first $\mathrm{Ag}$ monolayer has been completed, peak $\mathrm{II}_{\mathrm{a}}^{\prime \prime}$ turns into the hump of peak $\mathrm{II}_{\mathrm{a}}$ -

Otherwise, the electroreduction charge of the O-containing surface species for $E_{\mathrm{s}, \mathrm{a}}>1.0 \mathrm{~V}$ remains practically independent of $\tau$, whereas the charge of electrodeposited $\mathrm{Ag}$ increases regularly with $\tau$ in the $60 \mathrm{~s} \leqslant \tau \leqslant 600 \mathrm{~s}$ range, attaining a maximum value estimated as 1.6 times the $\mathrm{Ag}$ monolayer charge $\left(0.260 \mathrm{mC} / \mathrm{cm}^{2}\right)$.

When the potential hold is set at $0.03 \mathrm{~V}$, close to the hydrogen electrode potential (Fig. 3), the voltammograms show that the $\mathrm{H}$-electrodesorption charge firstly 

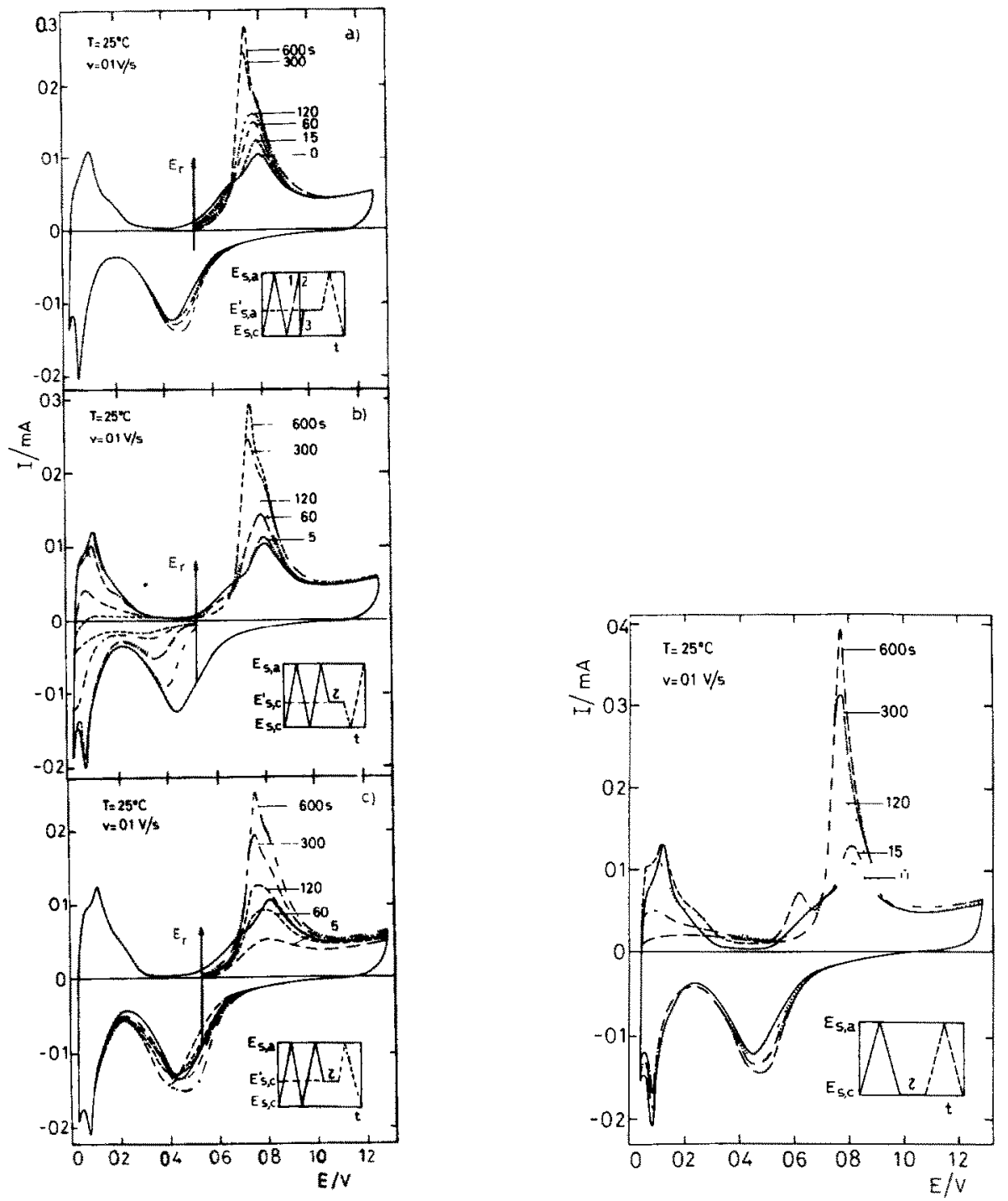

Fig. 2. Voltammograms on pc Rh run after including a potential hold at $E_{\mathrm{s}}^{\prime}$ during a time $\tau(0 \leqslant \tau \leqslant 600$ s). $1 \mathrm{M} \mathrm{H}_{2} \mathrm{SO}_{4}+10^{-5} M \mathrm{Ag}_{2} \mathrm{SO}_{4}$. (a) Potential hold $E_{\mathrm{s}}^{\prime}=E_{\mathrm{s} . \mathrm{a}}^{\prime}=E_{\mathrm{r}}$ applied during the electrooxidation sweep which continues after $\tau$. The potential scans preceding the potential hold were run at: $v=(1) 0.1$, (2) 1.0 and (3) $1.0 \mathrm{~V} / \mathrm{s}$. (b) $E_{\mathrm{s}}^{\prime}=E_{\mathrm{s} . \mathrm{c}}^{\prime} \cong E_{r}$. The potential hold is applied during the electroreduction sweep which continues after $\tau$. (c) $E_{\mathrm{s}}^{\prime}=E_{\mathrm{s}, \mathrm{c}}^{\prime} \cong E_{\mathrm{r}}$. The potential hold is applied during the electroreduction sweep, and after time $\tau$ the electrooxidation scan starts from $E_{s, a}^{\prime}$ upwards.

Fig. 3. Voltammograms on pc Rh run after including a potential hold at $E_{\mathrm{s}, \mathrm{c}}$ during a time $\tau(0 \leqslant \tau \leqslant 600$ s) betwcen each sweep. $1 \mathrm{M} \mathrm{H}_{2} \mathrm{SO}_{4}+10^{-5} \mathrm{M} \mathrm{Ag}_{2} \mathrm{SO}_{4}$. 
increases up to a maximum as $\tau$ increases and later decreases to the baseline current, whereas the $\mathrm{H}$-electroadsorption peak remains practically unaltered after Ag stripping. Likewise, the charge of peak $\mathrm{II}_{\mathrm{a}}-\mathrm{II}_{\mathrm{a}}^{\prime \prime}$ increases to reach a limiting value and immediately afterwards, the height of peak $\mathrm{II}_{\mathrm{a}}^{\prime}$ begins to increase. As peaks $\mathrm{II}_{\mathrm{a}}-\mathrm{II}_{\mathrm{a}}^{\prime \prime}$ and $\mathrm{II}_{\mathrm{a}}^{\prime}$ can be assigned to UPD and $\mathrm{OPD}$. $\mathrm{Ag}$ on an O-free $\mathrm{pc} \mathrm{Rh}$ surface, respectively, one concludes that at $0.03 \mathrm{~V}$, the $\mathrm{H}$-adatom layer is displaced progressively by electrodeposited $\mathrm{Ag}$ atoms. The anodic current contribution found in the $0.55-0.65 \mathrm{~V}$ range, which depends on both the concentration $\mathrm{of}^{+}$ion in solution and the characteristics of the potential programme, can be related to two simultaneous reactions, namely, the formation of $\mathrm{Rh}(\mathrm{OH})_{\mathrm{ad}}$, and the stripping of OPD Ag. However, the formation of $\mathrm{Rh}(\mathrm{OH})_{\text {ad }}$ is inhibited progressively due to the accumulation of $\mathrm{Ag}$ at $E_{\mathrm{s}, \mathrm{c}}^{\prime}$ as $\tau$ increases. The stripping voltammograms show definitely that the formation of bulk Ag starts only after electrodeposition of the amount of $\mathrm{Ag}$ related to peak $\mathrm{II}_{\mathrm{a}}$. Furthermore, as the amount of stripped $\mathrm{Ag}$ increases, the negative potential scan shows an increasing negative charge due to $\mathrm{Ag}$ electrodeposition overlapping the O-electroreduction charge. Therefore, from these results one concludes that bulk Ag electrodeposition can apparently occur only after the surface coverage by $\mathrm{Ag}$ adatoms $\left(\theta_{\mathrm{Ag}}\right)$ is slightly lower than two juxtaposed $\mathrm{Ag}$ layers $\left(\theta_{\mathrm{Ag}_{\mathrm{g}}} \cong 1.6\right)$.

The electrodeposition of $\mathrm{Ag}$ increases the threshold potential for the reaction yielding $(\mathrm{RhOH})_{\mathrm{ad}}$, whereas the presence of the O-containing surface species produces a substantial delay on the formation of Ag electrodeposits at UPD level (Figs. $2 \mathrm{c}$ and 3 ). For $\mathrm{pc} \mathrm{Rh}$ partially covered by $\mathrm{O}$-containing species, the growth of bulk $\mathrm{Ag}$ can occur without an appreciable amount of UPD Ag (Figs. 4a,b). The absence of stripping current peaks due to Ag UPD for certain values of $E_{\mathrm{s}, \mathrm{c}}$ is accompanied by the appearance of a hysteresis loop in the electroreduction scan which has been related to a nucleation and growth process $[1,10,11]$.

No dramatic changes in the voltammograms are observed by changing the temperature. The voltammograms run under conditions comparable to those of Figs. $2 \mathrm{a}$ and $2 \mathrm{c}$ but at $0^{\circ} \mathrm{C}$ either for clean or $\mathrm{O}$-containing $\mathrm{Rh}$ surfaces show that peaks $\mathrm{II}_{\mathrm{a}}$ and $\mathrm{II}_{\mathrm{a}}^{\prime \prime}$ largely overlap at $0^{\circ} \mathrm{C}$ on a prereduced pc $\mathrm{Rh}$. Conversely, current peaks $\mathrm{II}_{\mathrm{a}}$ and $\mathrm{II}_{\mathrm{a}}^{\prime \prime}$ remain distinguishable and of the same order of magnitude after holding the potential at $E_{\mathrm{s}, \mathrm{c}}^{\prime}=0.53 \mathrm{~V}$ for $\tau=180 \mathrm{~s}$ at $65^{\circ} \mathrm{C}$.

The competitive electroformation of $\mathrm{Ag}$ and O-containing surface layers on $\mathrm{Rh}$ can be explained in terms of the relative position of the potential window determined by the threshold potential for $\mathrm{Rh}(\mathrm{OH})_{\text {ad }}$ formation, i.e. $0.6 \mathrm{~V}$ (vs. RHE) in $1 \mathrm{M} \mathrm{H}_{2} \mathrm{SO}_{4}$ [8,9], and the value of $E_{\mathrm{r}}$. Thus, when $E_{\mathrm{r}}$ is lower than the threshold potential for $\mathrm{Rh}(\mathrm{OH})_{\text {ad }}$ electroformation, $\mathrm{Ag}$ electrodeposition takes place on a $\mathrm{Rh}$ electrode free of O-containing surface species. Then the overall reaction can be interpreted as the initial formation of the $\mathrm{Ag}$ submonolayer, followed by the completion of the Ag UPD layer, and finally bulk Ag growth.

Otherwise, when $E_{\mathrm{r}}$ is greater than the threshold potential for $\mathrm{Rh}(\mathrm{OH})_{\text {ad }}$ formation, $\mathrm{Ag}$ electrodeposition occurs on a $\mathrm{Rh}$ surface completely covered by an $\mathrm{O}$-containing surface species electroadsorbed monolayer. In this case, $\mathrm{Ag}$ elec- 

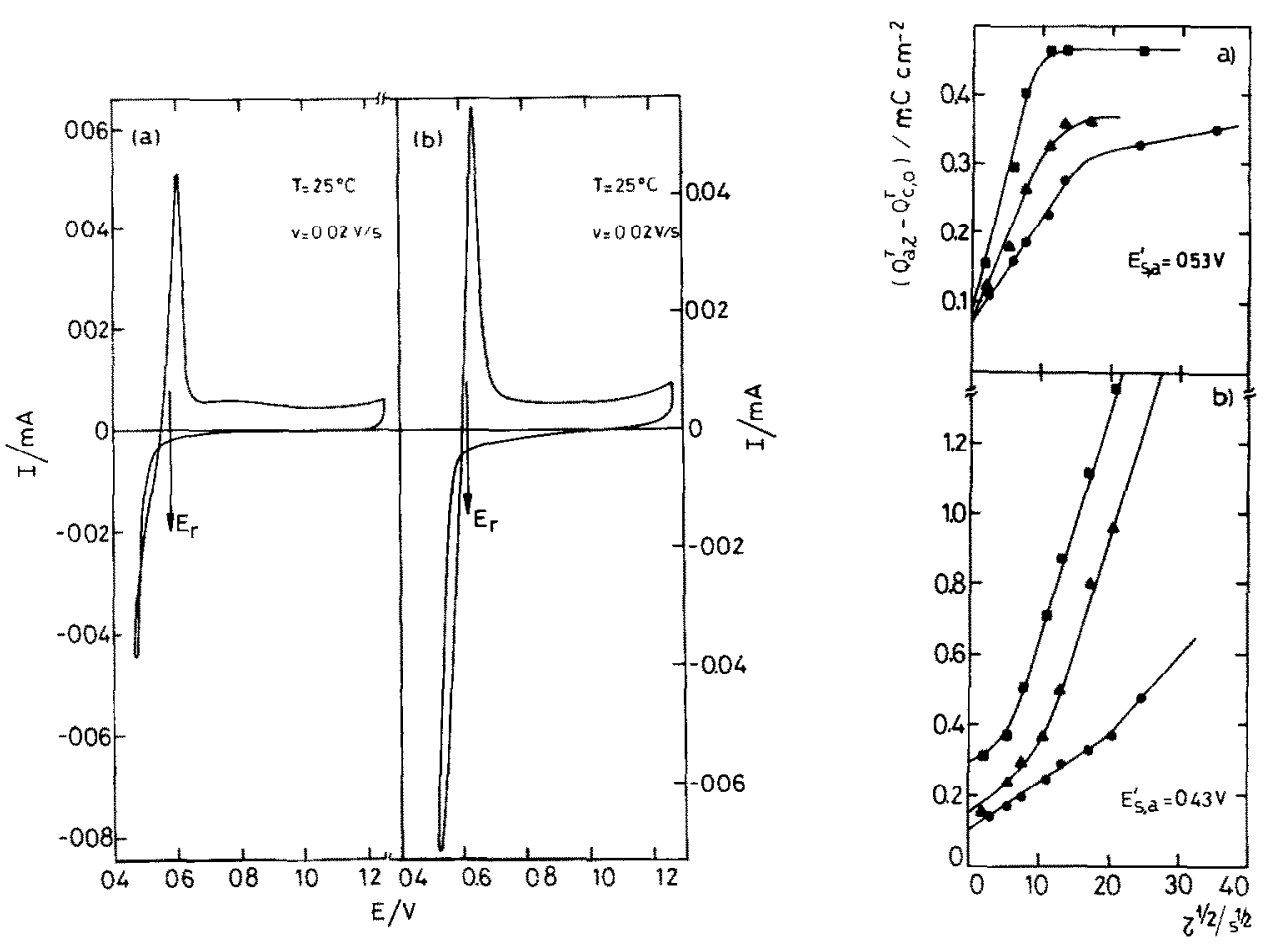

Fig. 4. Voltammograms on pe $\mathrm{Rh}$ exhibiting a loop in the lower potential region. (a) $1 \mathrm{M} \mathrm{H}_{2} \mathrm{SO}_{4}+2.5 \times$ $10^{-4} \mathrm{M} \mathrm{Ag}_{2} \mathrm{SO}_{4}$. (b) $1 \mathrm{M} \mathrm{H}_{2} \mathrm{SO}_{4}+10^{-3} \mathrm{M} \mathrm{Ag}_{2} \mathrm{SO}_{4}$.

Fig. 5. Dependence of $\left(Q_{\mathrm{a}, \tau}^{\mathrm{T}}-Q_{\mathrm{c}, 0}^{\mathrm{T}}\right)$ on holding time $\tau$ at two different $E_{s}^{\prime}$ and temperatures. $1 \mathrm{M}$ $\mathrm{H}_{2} \mathrm{SO}_{4}+10^{-5} \mathrm{M} \mathrm{Ag}_{2} \mathrm{SO}_{4} \cdot v=0.05 \mathrm{~V} / \mathrm{s} ;(\bullet) 15,(\Delta) 45,(\mathrm{E}) 65^{\circ} \mathrm{C}$.

trodeposition can proceed only immediately after free sites have been created at the $\mathrm{Rh}$ substrate through the electrodesorption of O-containing species. This implies two successive electron-transfer reactions at the same potential, that is O-electrodesorption and Ag electrodepostion. This explains the increase in voltammetric electroreduction charge, as seen in Fig. $2 c$.

The prevalence of each one of these situations results from a compromise between the $\mathrm{Ag}^{+}$ion concentration in solution, since this determines $E_{\mathrm{r}}$, and the voltammetry parameters, namely, $E_{\mathrm{s}, \mathrm{c}}, E_{\mathrm{s}, \mathrm{a}}$ and $v$, which in turn settle the amount of $\mathrm{O}$-species on the $\mathrm{Rh}$ electrode surface.

Finally, one can envisage the possible rate determining step of Ag electrodeposition through the dependence of voltammetric charges on $\tau$ at different potentials and tempcratures. In this case, only the overall positive charge $\left(Q_{\mathrm{a}, \tau}^{\mathrm{T}}\right)$ resulting after the holding time $\tau$, and the negative $\left(Q_{c, 0}^{\mathrm{T}}\right)$ charge without holding time are considered. The voltammetric data can be plotted as $\left(Q_{\mathrm{a}, \tau}^{\mathrm{T}}-Q_{\mathrm{c}, 0}^{\mathrm{T}}\right)$ vs. $\tau^{1 / 2}$ for different $E_{\mathrm{s}, \mathrm{a}}^{\prime}$ values (Figs. 5a,b). This charge difference can be related directly to 
the charge involved in Ag electrodeposition plus the charge required for creating bare $\mathrm{Rh}$ sites through O-electrodesorption. These plots for $\tau<100 \mathrm{~s}$ and $E_{\mathrm{s}, \mathrm{a}}^{\prime}=0.53$ $\mathrm{V}$ (Fig. 5a) approach linear relationships. The slope of these lines as well as the $\left(Q_{\mathrm{a}, \tau}^{\mathrm{T}}-Q_{\mathrm{c}, 0}^{\mathrm{T}}\right)_{\tau=0}$ value, that is the charge difference for $\tau=0$, both increase with temperature. For $\tau>100 \mathrm{~s}$, and $E_{\mathrm{s}, \mathrm{c}}^{\prime} \cong E_{\mathrm{r}}$, limiting charge values related to Ag UPD can be observed. Otherwise, for $E_{\mathrm{s}, \mathrm{c}}^{\prime}=0.43 \mathrm{~V}$, that is, $E_{\mathrm{s}, \mathrm{c}}^{\prime}<E_{\mathrm{r}}$, bulk electrodeposited $\mathrm{Ag}$ prevails and in this case the linear relationship holds over the whole time window of the experiments. The slope of the line changes with temperature according to an Arrhenius plot, which yields an experimental activation energy equal to $20 \pm 5 \mathrm{~kJ} / \mathrm{mol}$. The linear plots depicted in Fig. 5 and the activation energy value are consistent with a diffusion controlled process for any stage of $\mathrm{Ag}^{+}$ion electrodeposition. This is consistent with the fact that the value of the exchange current density for that reaction is about $1 \mathrm{~A} \mathrm{~cm}^{-2}$ [12].

\section{ACKNOWLEDGEMENTS}

This work was supported financially by the Consejo Nacional de Investigaciones Científicas y Técnicas of Argentina and the Comisión de Investigaciones Científicas de la Provincia de Buenos Aires. B.P.C. thanks the CONICET for a fellowship granted.

\section{REFERENCES}

1 A.R. Despic in R. Weil and R.G. Barradas (Eds.), Proceedings of the Symposium on Electrocrystallization, The Electrochemical Society, New Jersey, 1981, pp. 81-86.

2 D.M. Kolb in H. Gerischer and C.W. Tobias (Eds.), Advances in Electrochemistry and Electrochemical Engineering, Vol. 11, Wiley-Interscience, New York, 1978, p. 127.

3 G.W. Tindall and S. Bruckenstein, Electrochim. Acta. 16 (1971) 245.

4 S.H. Cadle and S. Bruckenstein, Anal. Chem., 43 (1971) 1858.

5 S. Stucki, J. Electroanal. Chem., 80 (1977) 375.

6 J.S. Hammond and N. Winograd, J. Electroanal. Chem., 80 (1977) 123; J. Electrochem. Soc., 124 (1977) 826.

7 R.G. Barradas, S. Fletcher and S. Szabo, Can. J. Chem., 56 (1978) 2029.

8 B. Parajón Costa, M.C. Giordano, C.D. Pallotta and A.J. Arvia, J. Electroanal. Chem., 139 (1986) 381.

9 C.D. Pallotta, N.R. de Tacconi and A.J. Arvia, Electrochim. Acta, 26 (1981) 261.

10 S. Fletcher, C.S. Halliday, D. Gates, M. Westcott, T. Swin and G. Nelson, J. Electroanal. Chem., 159 (1983) 267.

11 S. Jaya, T. Prasada Rao and G. Prabhakara Rao, Electrochim. Acta, 31 (1986) 343.

12 K.J. Vetter, Elektrochemische Kinetik, Springer Verlag, Berlin, 1961, p. 545. 